\title{
Professor František Tenora has passed away
}

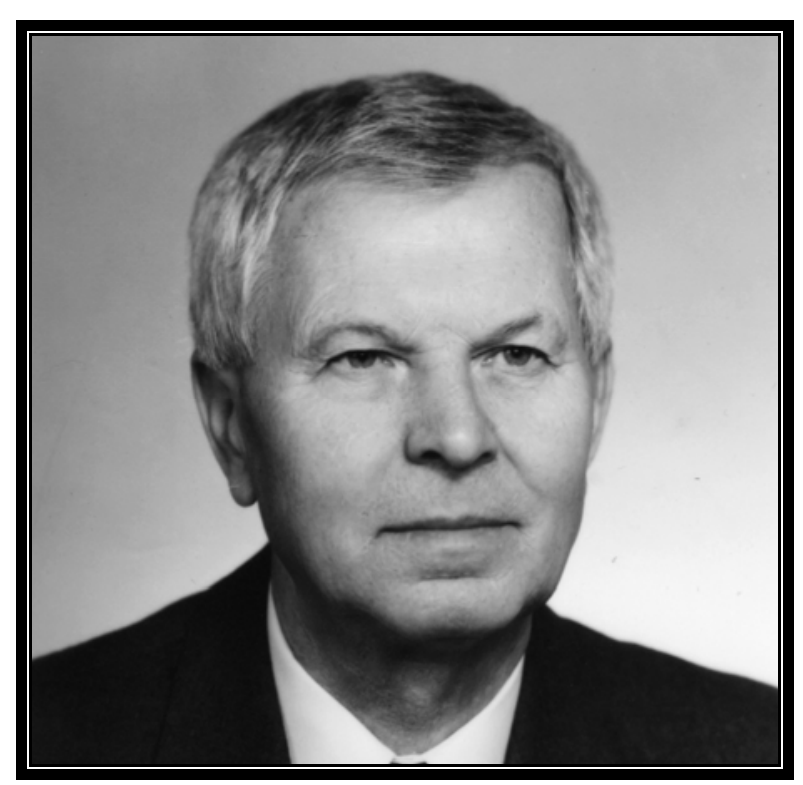

The Czech and Slovak parasitological community has recently received a sad announcement about a death of Professor RNDr. František Tenora, D.Sc. who passed away on August 22, 2011, shortly before his $81^{\text {st }}$ birthday. An outstanding and internationally known parasitologist was born on September 22, 1930 in Moravian township of Letovice (Czech Republic) and throughout his life he combined his scientific efforts with his native region of Morava. He completed undergraduate studies at the Masaryk University in Brno in 1953, with his diploma project focusing on hydrobiology. After completion of his studies, he was appointed an assistant professor at the Department of Zoology of the University of Agriculture in Brno (now the Mendel University in Brno). His professional career was directed to the field of parasitology: in 1962 and 1966, he was awarded the PhD. and RNDr. degrees, respectively, and having successfully defended his doctoral thesis "Evolution of rodent helminths", he was awarded D.Sc. in 1978.

The scientific degrees are accompanied by teaching career and both science and education represented parallels of his life. After the successful habilitation in 1966, Prof. Tenora was appointed Professor of Zoology in Mendel University in Brno in 1979. At the University, he held the Chair of Zoology during two decades $(1970$ - 1990), when he published nine textbooks, and from 1986 to 1989 he also served as the Vice-Dean for scientific activities, scientific education and foreign relations.
It seems that the breakthrough moment in his lifelong scientific direction occurred in 1953 when F. Tenora, as a young graduate, was given a task to pursue parasitology and helminthology from the Czech zoology nestor, Prof. Josef Kratochvíl. F. Tenora started to collaborate with two other acknowledged Bohemian helminthologists, Dr. Bohumil Ryšavý and Dr. Božena Erhardová, based at the Institute of Biology AS CR in Prague. As early as in 1955, he and his first student-specialist Vlastimil Baruš published several papers about rodent helminth parasites. Since then, Prof. Tenora was an author or co-author of more than 370 scientific and popular papers with a significant citation log out, and his ultimate work appeared in Parasitology Research in September, 2011. His love for science and helminthology in particular, his tenacity and perseverance lasted a lifetime. His broad scientific profile included number of theoretical and practical problems relating to the systematics, taxonomy and ecology of helminth parasites of wild and domestic vertebrates and man. Especially, Prof. Tenora was a world-renowned specialist in the field of rodent helminths, particularly tapeworms and he originally described a number of valid species new for science.

Scientific pilgrimage of Prof. Tenora is characterized by his broad international contacts and collaborations. From 1956 to 1998, he visited 22 Universities, Museum Departments and Research Institutes in Europe, Asia and Cuba. During those stays, he lectured on parasitology, supervised $\mathrm{PhD}$. students and co-operated on research projects with outstanding parasitologists - colleagues. For instance, he was appointed Visiting Professor at Hokkaido University, Sapporo, Japan and at Bernard University, Lyon, France. Moreover, he participated in two field expeditions to Afghanistan in 1966 and 1967.

For his diligence and charisma, Prof. Tenora has received and could enjoy various scientific awards. He has been presented with a number of honorary plaques and medals, not only from the Czech Republic but also from Universities and Scientific Societies abroad. On the occasion of his $80^{\text {th }}$ birthday, Prof. Tenora was awarded the Medal of Professor Hovorka from the Slovak Society for Parasitology at Slovak Academy of Sciences.

We are well aware of the fact that human life and nature are incomparably richer and cannot be described in several lines. As long-time collaborators and friends, we believe that the huge work of Prof. Tenora will long remember him. At least, his surname has become an eternal part of scientific names of helminth species described by him.

Vlastimil Baruš, Božena Koubková, and Marta Špakulová 